\title{
Persistency and treatment failure in newly diagnosed open angle glaucoma patients in the United Kingdom
}

\author{
Z Zhou, R Althin, B S Sforzolini, R Dhawan
}

Br J Ophthalmol 2004;88:1391-1394. doi: 10.1136/bjo.2003.037713

Aim: To determine utilisation patterns and calculate treatment failure and discontinuation rates in patients with open angle glaucoma treated in the United Kingdom with any of six groups of intraocular pressure (IOP) lowering agents.

Methods: The UK General Practice Research Database was used to identify newly diagnosed (after 1 January 1997) open angle glaucoma patients who were naive to therapy with any of six index drug groups: carbonic anhydrase inhibitors, latanoprost, miotics, sympathomimetics, timolol, and other (non-timolol) $\beta$ blockers. Analyses included drug treatment data for 1 year following diagnosis. Outcomes were (1) time to therapy failure, defined as either change in index drug (replacement or addition of therapy) or patient referral for surgery, and (2) time to therapy discontinuation, defined as either therapy failure or no refill of the index drug in a period twice that covered by the first prescription fill. Cox proportional hazard regression and Kaplan-Meier and life table methods were used to compare groups.

Results: Among the 2001 eligible patients, a $\beta$ blocker other than timolol was the most widely prescribed $(42 \%)$, followed by timolol $(32 \%)$, carbonic anhydrase inhibitors (10\%), and latanoprost (7\%). Compared to latanoprost, those treated with any alternative agent were significantly more likely to fail ( $p \leqslant 0.005$ for each comparison) and to discontinue ( $p \leqslant 0.05$ for each comparison) therapy. Failure rates ranged from $13 \%$ (latanoprost) to $45 \%$ (sympathomimetics), and discontinuation rates ranged from 30\% (latanoprost) to 63\% (miotics).

Conclusion: Latanoprost treated patients demonstrated lower rates of therapy failure and therapy discontinuation compared with patients treated with other widely used IOP lowering medications, including $\beta$ blockers.

$\mathrm{T}$ reatment of patients with open angle glaucoma focuses on lowering intraocular pressure (IOP) levels with the aim of delaying disease progression ${ }^{1-3}$ and slowing or preventing the progression of ocular hypertension to glaucoma. ${ }^{4}$ In patients newly diagnosed with glaucoma, ophthalmologists typically prescribe a topical ocular hypotensive agent in an effort to control IOP levels.

However, no ocular hypotensive medication can provide sustained IOP control unless the patient uses it continuously over time; therefore, therapy failure or discontinuation limits physicians' efforts to manage glaucoma. Population based cohort studies using claims records from managed care plans in the United States ${ }^{5-9}$ and a retrospective medical chart review study in Europe ${ }^{10}$ have found that time on treatment varies considerably across agents and that patients treated initially with latanoprost monotherapy remain on therapy significantly longer than those treated with comparator drugs.
The purpose of this study was to determine utilisation patterns and calculate treatment failure and discontinuation rates in patients with open angle glaucoma treated in the United Kingdom with any of six groups of IOP lowering agents.

\section{METHODS}

Newly diagnosed open angle glaucoma patients naive to ocular hypotensive therapy were included in this study. Data were derived from the General Practice Research Database (GPRD), which contains clinical information for approximately four million patients in the United Kingdom. GPRD data are recorded systematically by general practitioners and are sent anonymously to the Medicines Control Agency. Apart from small regional variations, the geographic distribution of practices participating in the GPRD is representative of the UK population in general, and age and sex distributions of patients are similar to those reported by the National Population Census. ${ }^{11}$ The quality of GPRD data has been found to be satisfactory for clinical research. Validation studies of outpatient referrals have documented $>90 \%$ concordance between clinical and computer records, ${ }^{12}{ }^{13}$ and a study of hypoglycaemia related hospitalisations found the principal diagnosis was present in $90 \%$ of computerised records. ${ }^{14}$

Although all data were anonymous, an independent science and ethics advisory group established by the Department of Health in the United Kingdom approved the study protocol. Two definition files were developed to classify patients by diagnosis and initial ocular hypotensive monotherapy. One of the authors (BSS, a clinical ophthalmologist in the United Kingdom) developed a diagnosis file of medical codes (OXMIS (Oxford Medical Information System) and READ codes) related to glaucoma in general and open angle glaucoma in particular and that excluded codes for non-open angle glaucomas (table 1). A drug therapy definition file consisting of GPRD codes was developed using British National Formulary codes 11.06 .01 through 11.06 .99 for ocular hypotensive drugs. These files were used to identify patients who received a prescription for an IOP lowering drug as first line monotherapy (index drug) on or after the date of their first diagnosis of open angle glaucoma. Patients were included if the initial diagnosis was recorded after 1 January 1997 and on or before 31 October 1999 and if GPRD data were available for at least 6 months before and 1 year after the diagnosis date. The initial inclusion date was chosen because the prostaglandin analogue latanoprost was introduced in the United Kingdom early in 1997; the final date was selected because the contractor was able to retrieve GPRD data only to the end of 31 October 2000, and at least 1 year of follow up information for each patient was required. Patients were classified into one of six index drug groups:

Abbreviations: GPRD, General Practice Research Database; IOP, intraocular pressure; OXMIS, Oxford Medical Information System 
Table 1 GPRD medical codes indicating a diagnosis of open angle glaucoma

\begin{tabular}{lll}
\hline Medical code & Description & $\begin{array}{l}\text { Number (\%) of } \\
\text { diagnoses* }^{*}\end{array}$ \\
\hline $\begin{array}{l}\text { OXMIS† codes } \\
\text { 3751 }\end{array}$ & Glaucoma, chronic & $73(1.1)$ \\
$3751 \mathrm{~A}$ & Glaucoma, open angle & $198(2.9)$ \\
$3751 \mathrm{PL}$ & Glaucoma, simple & $38(0.6)$ \\
3759 & Glaucoma & $3603(53.7)$ \\
READ codes & Glaucoma & $2428(36.2)$ \\
F45.00 & $\begin{array}{l}\text { Open angle glaucoma } \\
\text { F451.00 }\end{array}$ & $197(2.9)$ \\
F451000 & $\begin{array}{l}\text { Unspecified open angle } \\
\text { glaucoma }\end{array}$ & $1(<0.1)$ \\
F451100 & $\begin{array}{l}\text { Primary open angle } \\
\text { glaucoma }\end{array}$ & $5(<0.1)$ \\
F45z00 & $\begin{array}{l}\text { Glaucoma, not otherwise } \\
\text { specified }\end{array}$ & $171(2.5)$ \\
Total & & 6714 \\
\hline
\end{tabular}

*Diagnoses for 6295 patients; some patients had more than one diagnosis.

†OXMIS, Oxford Medical Information System.

carbonic anhydrase inhibitors, latanoprost, miotics, sympathomimetics, timolol, and other (non-timolol) $\beta$ blockers.

Outcomes related to persistency (time on therapy) with the index drug were time to therapy failure and time to therapy discontinuation. Treatment failure was defined as either a change in the index drug (replacement or addition of therapy) or patient referral for surgery. This measure reflects primarily a clinician's assessments of a drug's effectiveness and tolerability ${ }^{15}$ since patients can neither change their own prescriptions nor refer themselves for surgery. Therapy discontinuation was defined as either therapy failure or no refill of the index drug in a period twice the duration covered by the first prescription fill (default value 60 days). In addition to therapeutic failures, the category of discontinuers included patients who terminated therapy because of noncompliance (reflecting forgetfulness, inconvenience, or side effects) or who no longer required therapy (reflecting loss of vision or incorrect diagnosis).

Analyses included drug treatment data for the l year period following diagnosis. Survival functions (Kaplan-Meier and life table methods) were estimated for each outcome, and survival curves were plotted to give visual comparisons among treatment groups of the likelihood of remaining

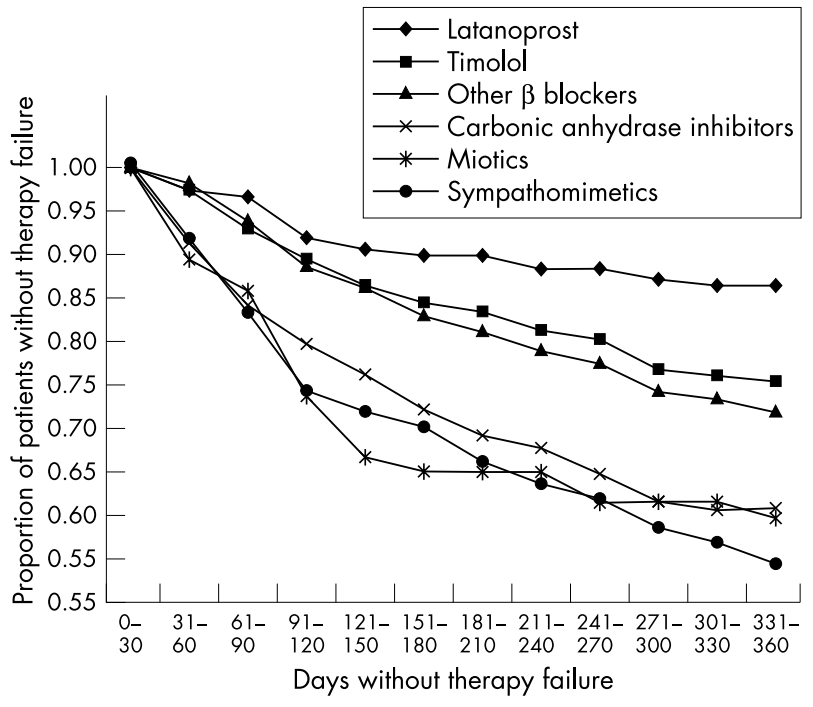

Figure 1 Plot of survival function for time to therapy failure. persistent. ${ }^{16}{ }^{17}$ Data were censored if either the end of follow up or the end of the study period occurred before a treatment failure or treatment discontinuation event was observed.

Multivariable Cox proportional hazards regression models were fitted for each outcome to determine whether the differences between latanoprost and any of the other five drug groups were significant after adjusting for age, sex, and length of period with up to standard medical records (satisfactory for research purposes). ${ }^{12}$ Adjusted hazard ratios, 95\% confidence intervals, and p values were derived from the models. Statistical analyses were performed using SAS version 8.2 (SAS Institute, Cary, NC, USA).

\section{RESULTS}

Overall, 2001 eligible patients were identified. $\beta$ Blockers were the most frequently prescribed first line monotherapy (32\% prescribed timolol; $42 \%$ prescribed other $\beta$ blockers) (table 2). Carbonic anhydrase inhibitors and latanoprost were prescribed for $10 \%$ and $7 \%$ of patients, respectively. Adjusted Cox regression model statistics for therapy failure and therapy discontinuation are shown in table 3. Compared with latanoprost treated patients, those treated with any alternative agent were significantly more likely to fail therapy (range of adjusted hazard rate ratios: 1.95 for timolol to 4.29 for sympathomimetics; $\mathrm{p} \leqslant 0.005$ for each comparison). Failure rates ranged from $13 \%$ (latanoprost) to $45 \%$ (sympathomimetics) (fig 1). Patients treated with alternative agents also were significantly more likely to discontinue therapy than were those receiving latanoprost (range of adjusted hazard rate ratios: 1.37 for timolol to 3.08 for miotics; $\mathrm{p} \leqslant 0.05$ for each comparison). Discontinuation rates ranged from $30 \%$ (latanoprost) to $63 \%$ (miotics) (fig 2).

Proportions of patients discontinuing therapy within 1 year stratified by reason for discontinuation (therapy failure or for other reasons) are shown in figure 3. Except among latanoprost treated patients, the majority of discontinuations in each index drug group were attributable to therapeutic failures.

\section{DISCUSSION}

We believe this is the first study to use a nationally representative sample of medical records from general practices in the United Kingdom to assess utilisation patterns and medication persistency in open angle glaucoma patients. Latanoprost treated patients demonstrated greater persistency than did those receiving alternative ocular hypotensive

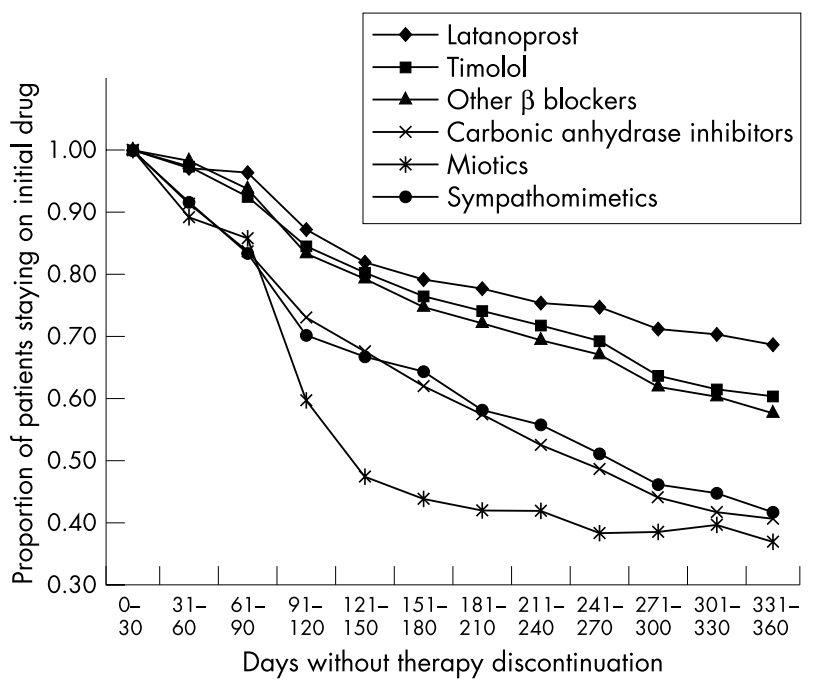

Figure 2 Plot of survival function for time to therapy discontinuation. 
Table 2 Sex and age distributions

\begin{tabular}{|c|c|c|c|c|c|c|c|}
\hline & & Latanoprost & Timolol & $\begin{array}{l}\text { Other } \beta \\
\text { blockers }\end{array}$ & $\begin{array}{l}\text { Carbonic } \\
\text { anhydrase } \\
\text { inhibitors }\end{array}$ & Miotics & Sympathomimetics \\
\hline & & No $(\%)$ & No (\%) & No (\%) & No (\%) & No (\%) & No (\%) \\
\hline $\begin{array}{l}\text { Total } \\
\text { Female }\end{array}$ & & $149(7)$ & $632(32)$ & $841(42)$ & $201(10)$ & $57(3)$ & $121(6)$ \\
\hline Ages & $\begin{array}{l}<65 \\
65-74 \\
>74\end{array}$ & $\begin{array}{l}16(11) \\
20(13) \\
44(30) \\
80(54)\end{array}$ & $\begin{array}{l}75(12) \\
88(14) \\
169(27) \\
332(53)\end{array}$ & $\begin{array}{l}111(13) \\
94(11) \\
221(26) \\
426(51)\end{array}$ & $\begin{array}{l}13(6) \\
27(13) \\
51(25) \\
91(45)\end{array}$ & $\begin{array}{l}8(14) \\
7(12) \\
21(37) \\
36(63)\end{array}$ & $\begin{array}{l}15(12) \\
19(16) \\
28(23) \\
62(51)\end{array}$ \\
\hline $\begin{array}{l}\text { Male } \\
\text { Ages }\end{array}$ & $\begin{array}{l}<65 \\
65-74 \\
>74\end{array}$ & $\begin{array}{l}19(13) \\
30(20) \\
20(13) \\
69(46)\end{array}$ & $\begin{array}{l}91(14) \\
80(13) \\
129(20) \\
300(47)\end{array}$ & $\begin{array}{l}131(16) \\
133(16) \\
151(18) \\
415(49)\end{array}$ & $\begin{array}{l}22(11) \\
31(15) \\
57(28) \\
110(55)\end{array}$ & $\begin{array}{l}4(7) \\
8(14) \\
9(16) \\
21(37)\end{array}$ & $\begin{array}{l}13(11) \\
15(12) \\
31(26) \\
59(49)\end{array}$ \\
\hline
\end{tabular}

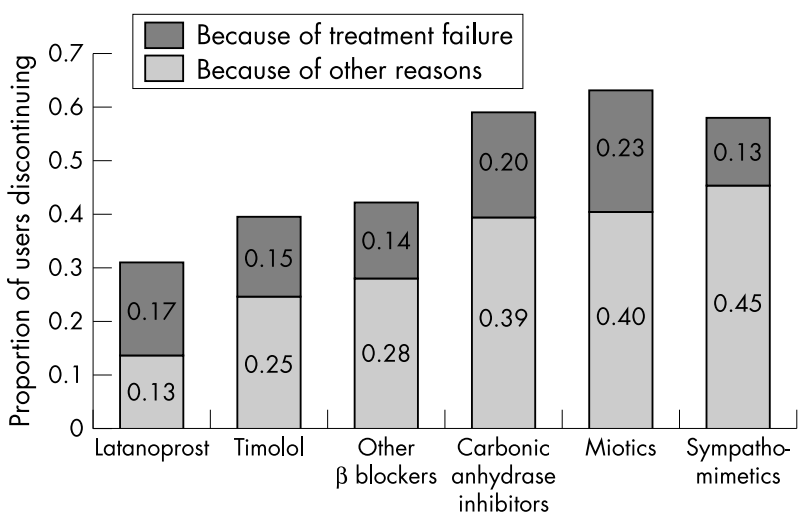

Figure 3 Proportion of patients discontinuing therapy within 1 year stratified by reason for discontinuation (treatment failure or for other reasons).

agents. The risks of both treatment failure and treatment discontinuation were significantly lower with latanoprost compared to alternative therapies.

The direction and magnitude of the present findings are consistent with results of previous comparative studies that found that patients are most persistent with latanoprost. ${ }^{5-9}$ For example, in studies that defined discontinuation of therapy as the point at which no further index drug refills occurred, rate ratios for discontinuation using latanoprost as the reference therapy ranged from 1.36 for timolol ${ }^{6}$ to 2.37 for carbonic anhydrase inhibitors. ${ }^{5}$ Compared with latanoprost, rate ratios for either discontinuation or change of therapy ranged from 1.40 for timolol $^{7}$ to 2.22 for carbonic anhydrase inhibitors. $^{5}$

Although the methodology of the present study did not identify reasons for therapy failure or discontinuation, it is possible to speculate about why persistency varied among therapeutic agents. Therapy failure reflects primarily clinicians' assessments of a drug's effectiveness and tolerability. ${ }^{15}$ Clinical trials have shown that latanoprost reduces IOP more effectively than timolol, ${ }^{18}{ }^{19}$ dorzolamide, ${ }^{20}$ or brimonidine ${ }^{21-23}$ and is highly tolerable. ${ }^{18-23}$ Therapy discontinuation, which was defined more broadly than therapeutic failure, reflects not only physician satisfaction with an agent's effectiveness and tolerability but also patient satisfaction with a drug's convenience and side effects. The tolerability of latanoprost and convenient once daily dosing regimen may contribute to patient persistency since poor medication compliance by glaucoma patients has been attributed to inconvenient dosing regimens as well as to ocular and systemic side effects. $^{24}$ In addition to discontinuations that reflected physician or patient assessments of an agent's effectiveness, tolerability, or convenience, discontinuations may have occurred for other reasons including patient forgetfulness, incorrect diagnosis, or vision loss.

The current research has several strengths and limitations. Strengths include the fact that analyses were based on records from the GPRD, a very large database representative

Table 3 Adjusted hazard rate ratios for risk of therapy failure and therapy discontinuation*

\begin{tabular}{|c|c|c|c|}
\hline & $\begin{array}{l}\text { Adjusted } \\
\text { hazard ratio }\end{array}$ & $95 \% \mathrm{Cl}$ & p Value \\
\hline \multicolumn{4}{|l|}{ Therapy failure } \\
\hline Latanoprost† & 1.00 & & \\
\hline Timolol & 1.95 & 1.60 to 2.38 & 0.005 \\
\hline Other $\beta$ blockers & 2.28 & 1.88 to 2.77 & 0.004 \\
\hline Carbonic anhydrase inhibitors & 3.60 & 2.92 to 4.44 & $<0.0001$ \\
\hline Miotics & 3.84 & 2.96 to 4.98 & $<0.0001$ \\
\hline Sympathomimetics & 4.29 & 3.45 to 5.34 & $<0.0001$ \\
\hline \multicolumn{4}{|l|}{ Therapy discontinuation } \\
\hline Latanoprost† & 1.00 & & \\
\hline Timolol & 1.37 & 1.06 to 1.78 & 0.05 \\
\hline Other $\beta$ blockers & 1.49 & 1.07 to 2.07 & 0.01 \\
\hline Carbonic anhydrase inhibitors & 2.52 & 1.16 to 5.44 & $<0.0001$ \\
\hline Miotics & 3.08 & 1.20 to 7.88 & $<0.0001$ \\
\hline Sympathomimetics & 2.45 & 1.16 to 5.19 & $<0.0001$ \\
\hline
\end{tabular}

*Hazard rate ratios and $95 \%$ confidence intervals (Cls) from adjusted Cox regression models. tReference group. 
of the UK population that has been widely used for epidemiological studies; results should be generalisable to the UK population as a whole. In addition, the impact of treatment for individual drugs could be assessed because the study cohort included only patients with newly diagnosed open angle glaucoma who were naive to monotherapy. Finally, persistency measures reflect both physician and patient assessments of ocular IOP lowering agents

Limitations include the fact that not all ocular hypotensive therapies dispensed actually are administered by patients; although the present study may have overestimated persistency by relying on information available in the GPRD, there is no reason to suspect that relative persistency rates across groups were affected. Because latanoprost became available in the United Kingdom only in early 1997 and data were available only through the third quarter of 2000, relatively few patients received latanoprost $(n=149)$; studies based on a larger sample and a longer, more recent follow up period are required to evaluate relative long term persistency across currently used ocular hypotensive agents in the United Kingdom. Moreover, latanoprost was approved in the United Kingdom only as second line therapy during the study period, and patients treated initially with this agent may have differed from those receiving other ocular hypotensives. Patients treated in response to temporary increases in IOP levels (for example, after surgery) may have been less likely to receive prostaglandins, thereby affecting the relative failure rates of latanoprost versus other agents. The fact that $3 \%$ of patients received miotics, an agent rarely used initially to treat open angle glaucoma, suggests that some errors in glaucoma classification may have occurred. Finally, a comparative cost effectiveness analysis was beyond the scope of the present study, and reasons for variability in persistency rates could not be evaluated because the research did not include patient and physician surveys.

In conclusion, latanoprost treated patients demonstrated significantly lower rates of therapy failure and therapy discontinuation compared with patients treated with other widely used IOP lowering medications, including $\beta$ blockers. The reasons for such differences and the long term impact of such variation on IOP control and healthcare costs should be further evaluated.

\section{Authors' affiliations \\ Z Zhou, R Althin, B S Sforzolini, R Dhawan, Pharmacia Corporation, Pfizer Inc, 100 Route 206 North, Mail Stop 133, Peapack, NJ 07977, USA \\ This research was supported by Pharmacia Corporation, a Pfizer company. \\ At the time this research was conducted, the authors were employees of} Pharmacia Corporation, a Pfizer company.

Correspondence to: Zhiyuan Zhou, PhD, Pfizer Inc, 100 Route 206 North, Mail Stop 133, Peapack, NJ 07977, USA; Zhiyuan.Zhou@pfizer. com

Accepted for publication 24 February 2004

\section{REFERENCES}

1 Heiil A, Leske MC, Bengtsson B, et al. Reduction of intraocular pressure and glaucoma progression: results from the Early Manifest Glaucoma Trial. Arch Ophthalmol 2002;120:1268-79.

2 Leske MC, Heij A, Hussein M, et al. Factors for glaucoma progression and the effect of treatment: the Early Manifest Glaucoma Trial. Arch Ophthalmol 2003;121:48-56.

3 Mao LK, Stewart WC, Shields MB. Correlation between intraocular pressure control and progressive glaucomatous damage in primary open-angle glaucoma. Am J Ophthalmol 1991;111:51-5.

4 Kass MA, Gordon M, Morley RE, et al. Compliance with topical timolol treatment. Am J Ophthalmol 2987; 103:188-93.

5 Dasgupta S, Oates V, Bookhart BK, et al. Population-based persistency rates for topical glaucoma medications measured with pharmacy claims data. Am J Manag Care 2002;8(suppl):S255-61.

6 Shaya FT, Mullins CD, Wong W, et al. Discontinuation rates of topical glaucoma medications in a managed care population. Am J Manag Care 2002;8(suppl):S271-7.

7 Spooner JJ, Bullano MF, Ikeda LI, et al. Rates of discontinuation and change of glaucoma therapy in a managed care setting. Am J Manag Care 2002;8(suppl):S262-70.

8 Reardon G, Schwartz GF, Mozaffari E. Patient persistency with topical prostaglandin therapy in the management of glaucoma. Clin Ther 2003;25: 1172-85.

9 Reardon G, Schwartz GF, Mozaffari E. Patient persistency with pharmacotherapy in the management of glaucoma. Eur J Ophthalmol 2003;13(suppl 4):S44-52.

10 Diestelhorst M, Schaefer CP, Beusterien KM, et al. Persistency and clinical outcomes associated with latanoprost and beta-blocker monotherapy: evidence from a European retrospective cohort study. Eur J Ophthalmol 2003;13(Suppl 4):S21-9.

11 Garcia Rodriguez LA, Pérez Gutthann S. Use of the UK Genera Practice Research Database for pharmacoepidemiology. Br J Clin Pharmacol 1998;45:419-25.

12 Jick H, Jick SS, Derby LE. Validation of information recorded on general practitioner based computerised data resource in the United Kingdom. BMJ 1991;302:766-78.

13 Jick $H$, Terris BZ, Derby LE, et al. Further validation of information recorded on a general practitioner based computerized data resource in the United Kingdom. Pharmacoepidemiol Drug Safety 1992;1:347-9.

14 Van Staa T-P, Abenhaim L. The quality of information recorded on a UK database of primary care records: a study of hospitalizations due to hypoglycemia and other conditions. Pharmacoepidemiol Drug Safety 1994;3:15-21.

15 Schwartz GF. Measuring persistency with drug therapy in glaucoma management. Am J Manag Care 2002;8(suppl):S237-9.

16 Lawless JE. Statistical models and methods for lifetime data. New York: John Wiley and Sons, 1982.

17 Cox DR, Oakes D. Analysis of survival data. London: Chapman and Hall, 1984.

18 Alm A, Stjernschantz J, for the Scandinavian Latanoprost Study Group. Effects on intraocular pressure and side effects of $0.005 \%$ latanoprost applied once daily, evening or morning: a comparison with timolol. Ophthalmology 1995; 102:1743-52.

19 Camras CB, for the United States Latanoprost Study Group. Comparison of latanoprost and timolol in patients with ocular hypertension and glaucoma: a six-month, masked, multicenter trial in the United States. Ophthalmology 1996; 103:138-47.

20 O'Donoghue EP, and the UK and Ireland Latanoprost Study Group. A comparison of latanoprost and dorzolamide in patients with glaucoma and ocular hypertension: a 3-month, randomised study. $\mathrm{Br} J$ Ophthalmol 2000;84:579-82

21 Kampik A, Arias-Puente A, O'Brart DPS, et al. Intraocular pressure-lowering effects of latanoprost and brimonidine therapy in patients with open-angle glaucoma or ocular hypertension: A randomized observer-masked multicenter study. J Glaucoma 2002;11:90-6.

22 Stewart WC, Day DG, Stewart JA, et al. Therapeutic success of latanoprost $0.005 \%$ compared to brimonidine $0.2 \%$ in patients with open-angle glaucoma or ocular hypertension. J Ocul Pharmacol Ther 2000;16:557-64.

23 Stewart WC, Day DG, Stewart JA, et al. The efficacy and safety of latanoprost $0.005 \%$ once daily versus brimonidine $0.2 \%$ twice daily in open-angle glaucoma or ocular hypertension. Am J Ophthalmol 2001;131:631-5.

24 Weinreb RN. Compliance with medical treatment of glaucoma. J Glaucoma 1992; 1:134-6. 